\section{THE BASIS FOR COMPENSATION OF THE SOLDIER FOR CARDIAC DISEASE *}

J. C. GiTtings, M.D. (Philadelphia) Licutenant-Colonel, M. C., U. S. Army; Chief of Medical Service AND

BERTNARD SMITH, M.D. (Los ANGeles) Captain, M. C., U. S. Army; Chief of Cardiovascular Division LAKEWOOD, N. J.

Nine months of experience on the disability board of General Hospital No. 9, where we have had unusual clinical opportunities for the study of patients suffering from various forms of cardiac disorder, have enabled us to draw some practical conclusions which may be of use to demobilizing boards.

The determination of disability hinges on diagnosis, so we may consider, in some detail, the classification of cases as they appear for discharge.

Functional cardiac disorder may be considered first. In this nomenclature, we have followed the revised manual of the Medical Department in preference to the other terms which are coming into more or less general use, such as "effort syndrome," and "neurocirculatory asthenia." The classification adopted covers various types under this heading, cardiac disorder functional, namely, constitutional inferiority; defective physical development; neurotic type; postinfectious type; postrheumatic type.

In the diagnosis of cases of cardiac disease the history is of the utmost importance and must be elicited with special care to avoid "suggestion." This was obviously necessary in dealing with the recruit who was desirous of avoiding service. At present, the danger seems less, since exaggerated claims of disability which existed prior to military duty tend to minimize the responsibility of the government and lessen the chances for compensation. With care, however, it is usually possible to arrive at a fairly accurate estimate of the soldier's physical and mental type before enlistment.

\section{CONSTITUTIONAL INFERIORITY WITH CARDIAC DIS ORDER FLNCTIONAL}

This general term is used to cover all forms of inferiority except that of chronic invalidism, which is of sufficient frequency to be given a separate heading as defective physical development.

These individuals give a history of more or less disability from earliest childhood, in which various illnesses may have played a rôle, but in the main they are essentially and primarily lacking in ambition, courage, energy, aggressiveness and endurance. As boys, they never played games requiring physical stamina, both because of a lack of the normal spirit of contest or sport, and because participation produced the syndrome which stamps the disorder. Usually there is associated mental deficiency in the sense that these patients appeared to be incapable of advancing beyond the lower educational levels under ordinary stimuli, and as they grew older were content with a low economic level in the job that made the fewest psychic and physical demands compatible with their economic needs.

Physical examination of such patients is essentially negative. Physical development usually is somewhat

- From U. S. Army General Hospital No. 9. below normal, and the muscle strength as shown by the Martin test may be below the standard; but more often the defect is not physical in a strict sense. Subjectively they complain on exertion of dyspnea; an early sense of general fatigue; cardiac palpitation; precordial pain, distress or tenderness, and vertigo, in the order of their frequency and importance. The area of cardiac dulness is not increased, tested by physical examination and by roentgen ray and the electrocardiograph. The pulse rate is unduly accelerated by any physical exertion and usually by excitement, although the time for the return to the normal rate for the individual may not be greatly prolonged.

The first sound at the apex as a rule is exaggerated and short, often suggesting the snapping first sound of mitral stenosis. At times a suggestion of a presystolic thrill can be felt in the erect position, and it is not hard to imagine that a faint presystolic murmur is heard. In the supine position the presystolic factors quickly disappear in contradistinction to the accentuation usually found in true mitral stenosis.

In this connection, it is interesting to note that the presystolic element in normal heart sounds, which Dr. Wiggers of Cornell University Medical College has demonstrated by the phonocardiograph, is a plausible explanation of the thrill and murmur. Whatever their origin, it is noteworthy that they are felt and heard almost invariably in the individual with the thin chest walls, which so greatly facilitate sound conduction. This type also exhibits with great frequency the basal systolic roughening or bruit, heard best in the second or third left interspace close to the sternum, and more pronounced in the supine position.

Regardless of the type of the chest, a soft systolic apical murmur is usually heard, loudest in the supine position and not transmitted, while cardiorespiratory murmurs are more or less common. The point of maximum intensity may be pronounced, and is often diffuse, depending both on the type of cardiac contractions and on the resiliency and thickness of the chest wall.

These "constitutional inferiors" are essentially useless for military purposes. Under ordinary conditions of recruiting the majority would be recognized and rejected by experienced army surgeons, not so much on account of the cardiac condition, but because of their evident inaptitude for service. Whatever the claims of these patients may be, it is a perfectly fair assumption that their condition has not been made materially worse by army service, because they have instinctively avoided severe exercise on account of its results. The soldier of this class who reports at sick call, or enters the hospital within one month or less of the time of his induction or enlistment, cannot be said to have suffered any real harm from his military efforts, and disability should be rated below one tenth to exclude the individual from compensation.

\section{DEFECTIVE PHYSICAL DEVELOPMENT WITH} CARDIAC DISORDER FUNCTIONAL

In these patients we have a physical defect more or less in evidence. Of most frequent occurrence is the so-called habitus enteropticus-the chest of the "carnivorous" type with relaxation of the abdominal muscles, while those of the chest and limbs are poorly developed. Usually the muscle strength test falls below the normal limits, and general nutrition is poor. The early history resembles that of the constitutionally 
inferior type so far as it concerns the ability to indulge in physical exercise, but there is not the same pronounced lack of ambition. Very often they have had serious and numerous illnesses during childhood, which may have been etiologic factors in the maldevelopment. This type must be carefully differentiated from that which suffers from the cardiac syndrome accompanying active tuberculosis. A comparatively small number of our patients exhibited definite, arrested tuberculous lesions. From the history it was clear that this had been the most important factor in the defective development.

The individual of the "defective physical development" type has often been encouraged or compelled by his physician or his parents to lead an inactive life because of an evident lack of physical stamina, or a belief that the heart was not "strong." For the same reason, as he gets older he selects the occupation that requires the least physical exertion, but his ambition and intelligence as a rule compel a higher economic return than that accepted by the constitutionally inferior type.

The actual cardiac findings on physical examination differ in no material degree from those found in Class 1. The subjective symptoms are the same, although the early sense of fatigue often plays a more prominent rôle than dyspnea.

The marked instances of this type likewise are essentially useless for military purposes and should never have been passed for military service. As a class, however, they go farther without a breakdown than do the constitutional inferiors, and in many instances are entitled to compensation because the breakdown occurs after several months of military duty, and in all probability results therefrom. Any other physical exertion, however, of the same degree would have produced the same result.

Most of the men belonging to these two groups are total abstainers from alcohol, not from any moral reason but because the effect is unpleasant. Tobacco and coffee apparently bear no essential relation to their symptoms. In the laboratory studies these patients show abnormal responses to sympathetic stimulation, and various degrees of disturbance in the glands of internal secretion. They stand at attention with muscles relaxed and the weight of the body resting on the pelvis. Their coordination is poor and they cannot be persuaded or forced to make the full effort at any time. Consequently they show very slight gains in strength, even after several months of daily exercises. Such men seek any excuse to avoid physical exertion and are often falsely accused of malingering. Careful electrocardiographic studies often show pronounced changes in the sympathetic control, such as could easily give rise to the disturbing symptoms. This causes one to doubt the wisdom of forcing men so generally below par to make their full effort unless they are under very close observation.

The following are given as sample histories of cases in these groups :

Case 1.-Defective physical development.-B., a soldier, aged 23, who had been in the service ten months and had performed no active duty, had had convulsions in infancy and had never been strong. His parents had been warned that he had a weak heart and that he must never be left alone. He had never walked over one mile a day. He had never taken any part in athletic games. He had had no serious illnesses. His parents were well. His mother was nervous. He had finished high school at 19 . He had had no regular occupation. He always has had precordial pain, shortness of breath, and rapid, pounding pulse on slight exertion. He was easily fatigued. He had never fainted, but was dizzy on sudden change of position. The heart was normal in size. There was a soft systolic blow at the apex, standing, which disappeared on lying down and after exercise. Electrocardiograph showed a sinus arrhythmia; rate, standing, 112; lying, after fifteen minutes, 88; after exercising, 130. There was a slight tremor of the hands. The thyroid was palpable. There were no eye signs. The basal metabolism was normal. Strength $:$ weight $=13^{i}$ After two months of daily exercises, strength: weight $=17.2$. There was marked precordial tenderness.

CASE 2.-Constitutional inferiority.-S., aged 25, who had been in the service four months and on active duty three days, was still in the fourth grade in school at 16 . $\mathrm{He}$ never could take part in any games or do any hard work on account of precordial pain, dizziness and fatigue. $\mathrm{He}$ had frequently changed work because of symptoms. He had worked as a rag sorter before service, and had earned $\$ 10$ a week. He had been satisfied and had liked the work because he could sit down and take his own time. His mother was nervous. His father was alcoholic. One brother was epileptic. The heart was normal in size. There were no murmurs. There was no tenderness. The thyroid was not palpable. There was marked tremor and a slight lidlag. The basal metabolism was normal. $\mathrm{He}$ could not learn to execute the command: "About face." He showed marked difficulty in all the balancing exercises. He knew little about the war. He did not read the newspapers because reading made him nervous. When he entered, strength: weight $=16.8 .^{1}$ After six weeks of daily exercises, strength: weight $=17.7$.

At times we find an individual whose cardiac disorder is out of all proportion to his physical defects and who is far above the constitutional inferior in intelligence and ambition. His former occupation, selected without regard to his health, made so few physical demands that he was totally unprepared for the severe strain of military training. Overzealous drill sergeants, or the hurried demands for even untrained men in France, forced this soldier at a pace beyond his limited endurance. His cardiovascular system apparently broke under the strain in spite of undoubted courage and a will to carry on. In this type can be accomplished the most striking cures, in a literal sense, from graduated exercises. Such patients should not be discharged until ample opportunity for cure has been afforded.

\section{CARDIAC DISORDER FUNCTIONAL, NEUROTIC TYPE}

In this we have the clinical picture of the neurotic or neurasthenic individual whose phobias have been directed to the heart. Ambition and intelligence are not lacking to the same extent as in Class 1. In place of these we find nervousness, unrest and hypersensitiveness, with the cardiac symptoms dominant. Palpitation, precordial pain and vertigo are more pronounced than actual fatigue, while the dyspnea is more subjective than objective. In the presence of slight enlargement of the thyroid, which sometimes occurs, differentiation of this type from that of true hyperthyroidism at times is difficult. In this connection if must be emphasized that slight enlargement of the thyroid, plus tremors of the hands and an easily excitable heart, do not constitute a syndrome on which to base a diagnosis of hyperthyroidism. The large majority of patients admitted to the hospitil with this diagnosis have been found to have a normal

1. The strength was estimated by the Martin spring balance test. Strength to weight normal values were obtained on 100 soldiers who had had over a year of hard training. The average $S / W$ value for 
basal metabolism. Hyperthyroidism to the extent of causing cardiac disturbance and nervous unrest, which at the same time fails to increase oxidation, is of a type that must be explained on purely hypothetic grounds.

A careful history of these patients of the neurotic type shows that the cardiac disorder dates back to early childhood, while the thyroid enlargement in cases of true exophthalmic goiter can be proved clearly to have been of recent development. In a few of our patients the history pointed to a definite exophthalmic goiter, which developed since childhood and which had apparently left a residuum of thyroid enlargement and exophthalmos. In the presence of a normal basal metabolism it was necessary to interpret the cardiac symptoms either as a sequel of the active exophthalmic goiter, or as a concomitant defect of the nature of that which forms the basis for all of these functional cases.

Whatever the explanation, these patients of the neurotic type are not suffering from hypersecretion of the thyroid gland, so far as can be determined with present-day facilities. They deserve compensation only when their ambition has led them to disregard symptoms in the attempt to carry on, with consequent damage to structures - cardiovascular, nervous, or whatever they be - which are fundamentally unfit for such a strain.

4. CARDIAC DISORDER FUNCTIONAL, POSTINFECTIOUS

Individuals of this type date the onset of their cardiac symptoms very definitely to an attack of one of the acute infections which are known to affect the myocardium at times, such as pneumonia, influenza, meningitis, diphtheria, and streptococcus infections. In the patient seen during the acute illness, definite evidence of myocardial involvement sometimes can be demonstrated, if we can accept such findings as an enlarged area of dulness with alteration in force and rhythm, and tile definite murmur of mitral insufficiency. After a few weeks, these may disappear entirely to be succeeded by the negative picture of functional cardiac disorder. Seen first at this stage, a diagnosis of myocarditis cannot be made with positiveness. However, the majority probably are essentially of the functional type throughout. If such patients can be followed for a sufficient period, it is again possible that a certain proportion will develop evidence of a true myocarditis; but failure to find it six months after infection would .warrant the belief that the symptoms of cardiac disturbance were dependent on other factors than irremediable myocardial degeneration. In a few doubtful cases the electrocardiograph has enabled us to differentiate true myocarditis, which would have been difficult to determine on purely clinical evidence.

In the majority of these patients the physical findings are the same as in the other groups. Subjectively the dyspnea on exertion is the most prominent symptom, while precordial pain and vertigo are less frequent. The latter facts are in noteworthy contradistinction to the findings in myocarditis on the one hand, in which precordial pain is quite common, and to the neurotic or constitutionally or physically inferior types on the other hand, in which both precordial pain and vertigo are frequently encountered.

The determination of the line of duty of such disabilities offers no difficulties when they follow acute infections occurring while on duty. Much more diffi- cult is the determination of the disability. Full consideration should be given to the individual who followed an active pursuit prior to enlistment and who carried on well during his military service until he contracted the infectious disease. $\mathrm{He}$ should be warned of the dangers of physical idleness on the one hand, and of over activity on the other. Under the worst of circumstances probably only a few will fail to revert to their former physical status, so that the compensation may safely be assumed to be "temporary."

How long to continue the physical training of these patients often is not easily determined. If proper facilities are available under suitable environment, and nostalgia from prolonged stay in hospitals is not a factor, many of them can be completely cured in from six to twelve weeks. For some, a "therapeutic furlough" restores morale and enables them to undertake the cure in an adaptable frame of mind. In not a few of these postinfectious cases, the history of events before enlistment and the presence of certain characteristics found in the group of the "constitutionally inferior" or in the type of the "defective physically" show that they were substandard even before the acquired infection. For such patients disability need not be large if their previous occupation has been light or sedentary, since their physical handicap will not weigh heavily on their wage-earning capacity. The more closely they approach the constitutionally or physically defective type, however, the less the chance for improvement from the exercises.

5. CARDIAC DISORDER FUNCTIONAL, POSTRHEUMATIC

This special classification was made before the signing of the armistice, in the belief that no patient whose cardiac symptoms dated from an attack of rheumatic fever could safely be permitted to return to full military duty, no matter how slight the evidence of myocardial damage, as well as on account of the tendency to recurrence under conditions of active campaign. All the cases in this group were studied with especial care to determine valvular and myocardial lesions. In a large proportion, no more evidence of definite pathologic changes could be found than in the preceding four groups, so that we were forced to place them under the class of functional disturbances, although it is reasonably certain that some will develop later definite myocardial lesions. For this reason, their compensation should be more liberal for any active vocation, and the possible contingencies-anticipated with the statement, "future problematical."

\section{HY PERT HYROIDISM}

We have had a comparatively small number of cases of true hyperthyroidism with persistent tachycardia, nervous unrest, turgescence and enlargement of the thyroid gland, marked tremors, more or less exophthalmos, and, above all, increased basal metabolism. Since treatment of true exophthalmic goiter, apart from surgical interference, primarily consists of complete physical and mental rest, while the worst thing that can be done for a victim of functional cardiac disorder (as Lewis points out) is to be put to bed, the differentiation of the two diseases is of vital importance from a therapeutic standpoint. This subject has been considered in an article by Major Peabody, which is in process of publication and need not be considered here. The disability resulting from true exophthalmic goiter should be absolute with the pros- 
pect, naturally, that full compensation will not be needed indefinitely.

\section{MIXED TYPES}

Not a few cases have been of a mixed type, when constitutional inferiority, defective physical development, and neurotic characteristics have all figured prominently in the patient's antecedents. These cases offer diagnostic difficulties; but disability and compensation are decided on the basis of the kind and amount of military duty performed, rather than on an academic accuracy of differentiation. We have had very little experience with the disturbance of cardiac action that follows exposure to gas, although the history at times showed a clear-cut, etiologic relationship. A separate study of gassed patients has been instituted.

\section{ORGANIC HEART DISEASE}

The description of these cases needs no special consideration. As usual, it is found that acute rheumatic fever, both before and after enlistment, figures largely as an etiologic factor. Several instances illustrated the perfectly well recognized, but not yet sufficiently known fact that the valvular lesion itself plays a negligible rôle in producing symptoms, so long as the myocardium is competent. The iron-worker or stevedore with valvular disease may accomplish his heavy day's work for years in absolute ignorance of his impending disability. One noteworthy case gave a history of a severe attack of rheumatic fever two years before enlistment. Subsequent to this he worked as a boiler-maker without any appament cardiac embarrassment. Two months after enlistment, having been examined and accepted in Class $\mathrm{A}$, he experienced an attack of suffocation with some blood spitting while on a march with full equipment from Brest to his regimental billets. At the time he was suffering from a "cold," but otherwise he had been perfectly well since enlistment. After a day's rest he recovered, but seven days later while at drill he had another and larger hemorrhage and was finally invalided home. We found a typical mitral stenosis, which, it is reasonably certain, had originated in the attack of rheumatism some two and a half years previously.

In the preparation of his certificate for discharge, the disability was put "not in line of duty," for the obvious reason that the length and type of service had been too short to produce such disability in any but a potentially ill man. The reviewing authority requested that this decision be reconsidered on the basis of the wording of General Order 47, War Department, which provides that any determined dis ability which occurs subsequent to a soldier's enlistment, after he has been examined and passed, shall be considered in line of duty, unless it can be shown unmistakably that the disability existed prior to military duty. The use of the word "disability" instead of "disease" offers ample opportunity to compensate a soldier who has been rendered hors de combat by cardiac disease.

The actual and relative number of instances of aortic regurgitation in overseas patients has been surprisingly large. Two explanations for this can be offered : first, that mitral murmurs are less easily overlooked, and consequently that their possessors are rejected, and second, that the stress of intensive training and the even greater stress of actual conditions of battle have aggravated lesions that were in their incipiency at the time the soldiers enlisted. In the absence of the concomitant signs usually found in this disease, the interpretation of a definite diastolic murmur at the left sternal border is open to some question, but can hardly be decided on any basis other than that of aortic insufficiency: Apparently this soft diastolic murmur is very frequently missed. The question has arisen as to the possibility of cardiorespiratory murmurs occurring during diastole when the patient checks his respiratory movements at the end of expiration. In one instaance of functional cardiac disorder in a thin-chested individual, a systolic cardiorespiratory murmur could be heard at the apex during respiration, but disappeared on the patient's holding his breath. In the same individual a distinct diastolic murmur was heard over the sternum at the end of both inspiration and expiration. This was atypical in time and quality and variable in intensity, however, and was undoubtedly produced by exocardial factors.

We have encountered two instances of congenital heart disease :

The first, patulous ductus arteriosus, occurred in an officer whose first cardiac symptoms of which he had any recollection occurred at the age of 8 , consisting of pain around the heart felt chiefly on deep inspiration. At school he was unable to play games vigorously without dyspnea and the precordial pain, but the disability was so slight as not to interfere with his work later as a laboratory worker and veterinary surgeon. In July, 1917, he was examined and passed for military service; did full duty in this country in the veterinary corps; was sent overseas in March, 1918, and continued to do full duty until September 15, when under fire and the coincident excitement he developed an extreme cardiac palpitation, dyspnea and nervousness, for which he was invalided home. When he entered this hospital, November 8 , he was feeling perfectly well when quiet, but complained of some dyspnea and palpitation on exertion. Examination of the heart showed the point of maximum intensity in the fifth interspace $9.5 \mathrm{~cm}$.; left border, $10 \mathrm{~cm}$. in the fifth interspace; right border, $3 \mathrm{~cm}$. in the fourth interspace from the midsternal line. There was an almost continuous "humming-top" murmur, loudest during systole, heard best in the third left interspace, transmitted for some distance to the left and upward. The pulmonary second sound was accentuated in the recumbent position, and a soft systolic murmur was heard at the apex. There was practically no cyanosis except after exercise. After nearly two months of rest the condition of this patient is apparently the same as before he entered the Army.

The second patient was an enlisted man who claimed that he had never suffered any disability and had worked in an iron foundry for eight months before enlistment. In June, 1918, two months after induction, he developed his first symptoms-dyspnea, cough and weakness-while on a hike from the port of debarkation to his rest billets. On admission to this hospital. in October, the area of cardiac dulness was not enlarged; there was slight accentuation of the second pulmonic sound and a rasping systolic murmur, loudest at the third left interspace close to the sternum, diminishing to a rather faint murmur at the apex and transmitted well to the left along the third and fourth ribs. There was no cyanosis nor any history of it. A diagnosis of defective interventricular septum, small lesion, seemed the most probable. The disability was rated with that of mitral regurgitation.

In spite of all that has been written, the fact still needs emphasis that most systolic murmurs at or near the apex are of functional, rather than organic, origin. In spite of many exceptions, the organic murmur is loudest at or near the apex, is constant, and is increased by exercise; and the functional murmur is apt to be as loud or louder at the base and is exaggerated in the supine position. To exclude cardiorespiratory murmurs, auscultation should always be 
done with the patient holding his breath midway between expiration and inspiration. Enlargement of the heart, making due allowance for the size of the individual and the shape of the heart and the chest, points to the organic lesion. Marked accentuation of the second pulmonic sound and transmission to the left axilla are significant but by no means infallible criteria. A few cases will almost elude analysis. In these, the previous occurrence of rheumatic fever often will turn the scale in favor of the diagnosis of an organic lesion. In general, also, we have observed that the acceleration of the heart's action, both at rest and after exercise, is less in the case with the true organic lesion than in the functional disorder.

The typical presystolic murmur of mitral stenosis would rarely be missed if the heart were ausculted with the patient lying down. This is of sufficient importance to warrant the use of examining tables. The only disadvantage would be the misinterpretation of the accentuation of the functional systolic murmur in the supine position. The differentiation of the Flint murmur with aortic regurgitation from that of a coincident mitral stenosis usually can be made on the crescendo character ending in the snapping first sound. At times, however, the distinction is difficult to make. The stenotic murmur usually is sharply localized at or just to the right of the point of maximum intensity. The Flint murmur has a wider distribution, at times extending even to the left border of the sternum. Both the aortic regurgitant and the Flint murmurs are heard better, as a rule, in the erect than in the supine position, while the murmur of mitral stenosis is affected in the reverse order. Definite enlargement at the base of the heart would be prima facie evidence of stenosis. Unfortunately, this is difficult to determine with accuracy, and even the orthodiagraphic plates are misleading in many instances. When all physical findings are inconclusive, the probability may be assumed that a double lesion would produce more disability than simple aortic insufficiency, unless the valvular lesions were of recent origin.

Pericardial lesions have been recognized in only a few cases. In one case which resulted from a high explosive shell wound with a definite history of a suppurative lesion, the only residual signs were a short and sharp first sound without murmurs, and a definite fixation of the heart on change of position. Another case had been diagnosed on the presence of well marked enlargement and Broadbent's sign. Mitral insufficiency was also evident, but was thought to be due to old valvulitis. This patient was killed in an automobile accident, and the diagnosis of pericarditis was confirmed at necropsy. The mitral leaflets were absolutely normal, however, and the insufficiency was purely relative.

In the majority of the cases we have seen, the valvular disease undoubtedly existed at the time of enlistment, and was overlooked by the examining surgeon. The disability which succeeded after several months of military duty therefore was considered to be in line of duty. In determining the degree of disability with a view to compensation, there should be due consideration for the expectancy of life and ability to continue in a wage-earning capacity, as well as for the type of work of which the soldier is capable. It is believed to be the intention of the Federal Board for Vocational Education to compel the soldier to take advantage of opportunities for learning a new trade, by refusing compensation for total disability in the case of a soldier who is physically able to carry on a lighter occupation after instruction, but is unwilling to take the instruction. Until the machinery for this is in good working order, it is manifestly unfair to the soldier to penalize him by compelling him to continue a laborous pursuit because compensation is not sufficient to enable him to live without it, so that disability should cover these needs, until provision can be made for vocational reeducation.

\section{OCCUPATION}

We have emphasized the importance of the history in determining the types of functional cardiac disease, and one of the most important items in the history is the previous occupation. In the series so far reviewed, over 60 per cent. of those with functional cardiac disease have earned their living in prewar days in light or sheltered occupations. Of the organic cases, over 80 per cent. have selected active economic pursuits, in spite of the more or less damaged condition of their hearts. As Major Peabody has elsewhere pointed out, those with functional cardiac disease always take particular care not to injure themselves by hard manual labor. The much more unfortunate victim of organic heart disease does not hesitate to take chances, in spite of great limitation of his cardiac reserve.

\section{EXERCISE}

We must emphasize the fact that our studies have demonstrated beyond reasonable doubt that the individual suffering from functional cardiac disorder of any type does better on exercise than on rest; that the exercise must be graduated from the smallest possible beginning, and that these patients require constant encouragement to overcome their natural aversion to, and fear of, the symptoms produced by exertion. These symptoms have resulted in their leading inactive lives until the vicious cycle has been definitely established. The cycle cannot be broken successfully by revolutionary methods. As has been stated, many of them fail to respond to any discoverable incentive. A few react to the gospel of muscular development, and it is an interesting speculation as to how many might have been saved a lifelong disability had the gospel been rightly preached at the impressionable age. The neurotic type is too self-centered and neurasthenic to be reached in ordinary class work. The approach to this individual must be psychiatric as well as physical. The postinfectious type offers the greatest possibilities for real cure, with the proviso that especial care must be exercised to avoid overstrain. True myocardial lesions in the light of our present knowledge demand rest until all definite signs have disappeared. Finally, it must be noted that graduated exercise offers a much better cardiac tonic for cases with valvular defects than years of clinical teaching have led us to believe. It cannot be too strongly insisted, however, that the fool rushing in where angels (of the past) feared to tread may work incalculable damage. Caution and skilled knowledge are prerequisities of successful treatment.

Tuberculosis.--Tuberculosis is the great scourge of civilized mankind. Unless more progress is made in fighting the disease, $9,000,000$ of the $100,000,000$ persons in the United States may be expected to die of it.-Health Bulletin, Newark, N. J. 